\title{
Giordano Bruno e la Francia, a cura di Rosanna Gorris Camos, introduzione di Davide Bigalli
}

\section{Dario Cecchetti}

\section{(2) OpenEdition}

1 Journals

\section{Edizione digitale}

URL: http://journals.openedition.org/studifrancesi/6254

DOI: 10.4000/studifrancesi.6254

ISSN: 2421-5856

\section{Editore}

Rosenberg \& Sellier

\section{Edizione cartacea}

Data di pubblicazione: 1 novembre 2010

Paginazione: $543-544$

ISSN: 0039-2944

\section{Notizia bibliografica digitale}

Dario Cecchetti, «Giordano Bruno e la Francia, a cura di Rosanna Gorris Camos, introduzione di Davide Bigalli», Studi Francesi [Online], 162 (LIV | III) | 2010, online dal 30 novembre 2015, consultato il 10 janvier 2021. URL: http://journals.openedition.org/studifrancesi/6254 ; DOI: https://doi.org/10.4000/ studifrancesi.6254

Questo documento è stato generato automaticamente il 10 janvier 2021.

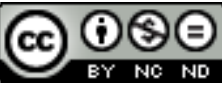

Studi Francesi è distribuita con Licenza Creative Commons Attribuzione - Non commerciale - Non opere derivate 4.0 Internazionale. 


\title{
Giordano Bruno e la Francia, a cura di Rosanna Gorris Camos, introduzione di Davide Bigalli
}

\author{
Dario Cecchetti
}

\section{NOTIZIA}

AA. VV., Giordano Bruno e la Francia, Atti della giornata di studi, Verona, 19 aprile 2007, a cura di Rosanna GORRIS CAMOS, introduzione di Davide BIGALLI, Manziana (Roma), Vecchiarelli Editore, 2009, pp. 117.

1 I saggi qui raccolti non solo affrontano questioni concernenti il soggiorno di Bruno in Francia, ma rintracciano i segni che la lezione bruniana ha lasciato nella cultura francese dei secoli seguenti. Nel saggio che apre la raccolta, Jean BALSAMO (Le système et la mosaïque: Giordano Bruno et ses lecteurs français, pp. 15-33), ricostruendo le vicende editoriali delle opere bruniane nel contesto parigino ed evidenziando il gioco delle dediche, offre un quadro dell'intrecciarsi folto e complicato di rapporti con i lettori francesi, fra cui troviamo i grandi rappresentanti della cultura e personalità politiche come Enrico III. Seguendo la fortuna di Bruno attraverso il possesso di opere e attraverso le pubblicazioni nel Sei e soprattutto nel Settecento, Balsamo può parlare dello scoppio di una vera e propria 'brunomania' nel secolo dei Lumi. Simonetta BASSI (Giordano Bruno nell'interpretazione di Pierre Bayle, pp. 35-52) studia la presenza di Bruno nel Dictionnaire di Bayle, individuando le fonti delle informazioni bayliane, spesso basate su notizie di seconda mano, non prive di errori, e mette in luce come nell'apologia dell'ateo virtuoso Bayle ridimensioni la portata filosofica di Bruno, per soffermarsi a titolo di exemplum sulle vicende che lo hanno portato al rogo. Fabrizio MEROI ("Jordanus m'a dit...». La testimonianza di Guillaume Cotin su Giordano Bruno, pp. 53-58) studia la testimonianza di Guillaume Cotin, bibliotecario dell'abbazia di Saint-Victor, che tra il dicembre 1585 e il febbraio 1586 ebbe delle conversazioni con il filosofo 
nolano. Queste conversazioni debitamente annotate nel diario del bibliotecario sono tra le non molte testimonianze dirette su Giordano Bruno in Francia. Elisabetta SCAPPARONE («Une religion politique»? Giordano Bruno e Jacopo Corbinelli: frammenti di un dialogo, pp.59-72), sollecitando anch'essa le fonti testimoniali per una più corretta $\mathrm{e}$ approfondita interpretazione del pensiero bruniano, studia i rapporti fra Corbinelli e Bruno, due esuli impegnati entrambi nell'elaborazione di una controcultura. In particolare, in questo studio, è interessante l'indagine sul machiavellismo e sull'antimachiavellismo in Francia. Nicoletta TIRINNANZI («Repleti aristotelico spiritu». Interlocutori e critici di Bruno nelle lezioni mnemotecniche del 1582, pp. 73-82) studia il ciclo di lezioni bruniane tenute a Parigi nel 1582, delineando le figure degli interlocutori e dei critici che a queste lezioni partecipano, in particolare rivolgendo l'attenzione a quei rappresentanti di un'alta cultura attardata, dove riaffiorano le posizioni espresse un quarantennio prima nei confronti di Pierre de La Ramée da parte di ortodossi aristotelici. Alessandra PREDA (Il 'barconaccio' in alto mare: la prima traduzione francese del "Candelaio», pp. 83-99) si occupa del Candelaio, della sua fortuna editoriale francese e della sua più antica traduzione, interessandosi ai risvolti semantici di questa riscrittura, che si evidenziano nell'impatto che il lessico comico bruniano esercita sul traduttore che prova difficoltà non risolte, ma anche dimostra volontà di innovazione linguistica. Laura RESCIA («Le Ciel réformé» de L.V. de Vougny (1750): appunti su una traduzione parziale dello «Spaccio della bestia trionfante». pp.101-117) anch'essa si occupa di traduzione francese del testo bruniano, apportando documentazione per ricostruirne la circolazione nel mondo libertin ed evidenziando come la raffigurazione di Bruno sostenitore del libero pensiero troverebbe origine nel libertinismo erudito prima che nelle costruzioni dell'anticlericalismo ottocentesco. 